\title{
Long term effect of erythromycin therapy in patients with chronic Pseudomonas aeruginosa infection
}

Takeshi Fujii, Jun-ichi Kadota, Kaoru Kawakami, Keiko Iida, Ryo Shirai, Makoto Kaseda, Sadahiro Kawamoto, Shigeru Kohno

\begin{abstract}
Background - Diffuse panbronchiolitis is a chronic infection of the lower respiratory tract common among the Japanese people, with a persistent Pseudomonas aeruginosa infection in the late stage and sustained neutrophil retention in the airways. The long term effect of erythromycin was examined retrospectively in a group of patients with diffuse panbronchiolitis, with and without $P$ aeruginosa infection, and the relationship between drug-induced bacterial clearance and clinical improvement was investigated.
\end{abstract}

Methods - The history, daily volume of sputum, type of organisms in sputum cultures, pulmonary function tests, arterial blood gas tensions, and chest radiographs were compared in 16 patients with diffuse panbronchiolitis with $P$ aeruginosa infection and 12 without. The total and differential cell counts in the bronchoalveolar lavage (BAL) fluid were compared in 14 of the 28 patients (five of whom were infected with $P$ aeruginosa) before and after 1-12 months of treatment with erythromycin $(600 \mathrm{mg} / \mathrm{day})$. The outcome of treatment in patients showing clearance of organisms on repeated sputum cultures was compared with that in those demonstrating persistence of bacteria in the sputum and patients with normal flora.

Results - Erythromycin improved respiratory function and arterial blood gas tensions irrespective of the presence or absence of $P$ aeruginosa in the sputum. Treatment also resulted in a reduction in the BAL fluid total cell count and the percentage of neutrophils in both groups of patients. There were no differences between patients in whom the bacteria cleared and those with persistent bacteria or patients with a normal flora with regard to the degree of improvement of respiratory function, arterial blood gas tensions, and BAL fluid cell composition.

Conclusion - The results suggest that the efficacy of erythromycin in diffuse panbronchiolitis may be due to an anti-inflammatory effect, independent of $P$ aeruginosa infection or bacterial clearance.

(Thorax 1995;50:1246-1252)

Keywords: erythromycin, diffuse panbronchiolitis, Pseudomonas aeruginosa.
Diffuse panbronchiolitis is a chronic infection of the lower respiratory tract first reported in Japan in 1969 by Yamanaka et al. ${ }^{1}$ It is more common in Japan than in western countries where only a few cases have been reported. ${ }^{23}$ This is probably due to the close association of diffuse panbronchiolitis with HLA B54 or its related haplotype in the Japanese population and the genetic background of mongoloid races such as Japanese, Chinese, and Koreans. ${ }^{4}$ The male to female ratio of the disease is more than $2: 1$, and the age of onset is variable. ${ }^{5}$ The main features of diffuse panbronchiolitis include chronic cough, copious sputum, shortness of breath, wheezing and hypoxaemia, and about $75 \%$ of patients have chronic sinusitis. The chest radiograph shows small nodular shadows in both lungs often associated with hyperinflation. Respiratory function tests show a mixed ventilatory impairment with a predominantly obstructive disturbance. Histopathologically the disease is characterised by thickening of the walls of the respiratory bronchioles and infiltration of inflammatory cells. ${ }^{5}$ Isolation of Haemophilus influenzae and Streptococcus pneumoniae from the sputum occurs early in the course of the disease and this can change to $P$ aeruginosa as the disease progresses. $P$ aeruginosa is detected in $55 \%$ of patients on the first sputum culture, increasing to $82 \%$ during the late stage of diffuse panbronchiolitis. ${ }^{6}$ The condition progresses insidiously and the prognosis, especially after infection with $P$ aeruginos $a$, is considered poor. The clinical features of persistent $P$ aeruginosa infection and neutrophil retention in the airways in diffuse panbronchiolitis ${ }^{7}$ are similar to those of cystic fibrosis, the most common lethal inherited condition among Caucasians. ${ }^{8-10}$ Several $P$ aeruginosa products such as exotoxin $\mathrm{A}$, protease, elastase, leucocidin, phospholipase $\mathrm{C}$, exoenzyme $\mathrm{S}$ and numerous haemolisins can cause airway damage, ${ }^{11-13}$ and are thought to play an important part in the development of bronchiectasis. ${ }^{14}$ In addition, neutrophil accumulation in the airway can contribute to lung damage through the release of protease, free oxygen radicals, and other degradative enzymes. ${ }^{1516}$

Erythromycin is a macrolide antibiotic commonly used in patients with respiratory infections, but is not a potent antibiotic for treating $P$ aeruginosa infection since the minimum inhibitory concentration is usually more than $100 \mu \mathrm{g} / \mathrm{ml}$ and the proliferation of $P$ aeruginosa is never inhibited. ${ }^{17}$ However, several \\ 30 August 1995
}


Japanese studies have shown the therapeutic benefits of the use of a "low dose and long term" erythromycin regimen in diffuse panbronchiolitis $^{18}$ leading to a significant improvement in clinical symptoms, radiological, and laboratory tests. ${ }^{19}$ In 1987 a team of researchers from the Japanese Ministry of Health and Welfare for Specific Diseases reported that the 10 year survival rate was $12.4 \%$ in cases infected with $P$ aeruginos $a$ and $73.1 \%$ in cases without $P$ aeruginosa infection. Erythromycin treatment increased the 10 year survival to more than $90 \% .^{20}$ However, no studies have compared the effect of erythromycin treatment in patients with and without $P$ aeruginosa infection, nor has the relationship between erythromycin-induced clearance of the organism in the sputum and clinical improvement been examined. In the present study we therefore divided patients with diffuse panbronchiolitis into two groups for the purpose of verifying that there are differences in the effects of "low dose and long term" erythromycin therapy in patients with and without $P$ aeruginosa infection, and evaluated the effect of erythromycin on the clinical course of diffuse panbronchiolitis, bronchoalveolar lavage (BAL) findings, and sputum clearance of organisms.

\section{Methods}

PATIENT POPULATION

Twenty eight patients with diffuse panbronchiolitis participated in the study. The disease was confirmed by open lung biopsy in 14 of the 28 patients, including four patients who did not meet the clinical criteria. The remaining patients were diagnosed clinically according to the diffuse panbronchiolitis diagnostic guidelines of the Japanese Ministry of Health and Welfare. These criteria are: (1) the presence of chronic productive cough and dyspnoea on exertion; (2) physical signs with rales and rhonchi; (3) diffusely disseminated fine nodular shadows, mainly in the lower lung fields with hyperinflation of the lungs on chest radiography; (4) the presence of at least three laboratory abnormalities among the following four abnormalities: forced expiratory volume in one second $\left(\mathrm{FEV}_{1}\right)<70 \%$ predicted, vital capacity (VC) $<80 \%$ predicted, residual volume (RV) $>150 \%$ predicted, RV/total lung capacity (TLC) $>45 \%$, or arterial oxygen tension $\left(\mathrm{PaO}_{2}\right)<10.6 \mathrm{kPa}$. The diagnosis of chronic non-allergic sinusitis was made based on radiological and nasal discharge examinations. All patients were evaluated by clinical history, physical examination, total daily volume of sputum, sputum culture, pulmonary function tests, arterial blood gas tensions, and chest radiography. BAL was performed in 14 of the 28 patients before and 12 months after the commencement of erythromycin therapy.

\section{ERYTHROMYCIN THERAPY}

All patients received $200 \mathrm{mg}$ erythromycin orally three times per day for at least 12 months. Patients were instructed on each outpatient visit to take the medication every eight hours and were provided with a four week supply at each visit. They were instructed to return any remaining tablets on each visit so that the number of the remaining tablets could be checked. None were treated with corticosteroids or antibiotics other than erythromycin during the course of the study.

\section{SPUTUM CULTURE}

Sputum culture was performed every 1-3 months before enrolment and during treatment to detect the organism causing airway infection or significant pathogens. The purulent sputum was solubilised in semialcaliproteinase (Sputazym ${ }^{\circledR}$, Kyokuta Co, Tokyo, Japan) and quantitative examination of the bacteria was achieved through a tenfold serial dilution. The number of bacteria was expressed in colony forming units. ${ }^{2122} P$ aeruginosa was identified using the automicrobic system (Vitek Inc, USA).

\section{BRONCHOALVEOLAR LAVAGE}

After obtaining informed consent intramuscular atropine $(0.5 \mathrm{mg})$ was administered followed by local anaesthesia of the airway with $2 \%$ lignocaine. Examination of the airway was performed with a flexible fibreoptic bronchoscope (Olympus, BF-P20 type; Olympus Corporation, Tokyo, Japan). The bronchoscope was wedged into one of the subsegmental bronchi of the right middle lobe and $150 \mathrm{ml}$ sterile $0.9 \% \mathrm{NaCl}$ was infused at $37^{\circ} \mathrm{C}$ in three $50 \mathrm{ml}$ aliquots and gently aspirated immediately after each infusion. The recovered BAL fluid was pooled, passed through a double layer of gauze to remove gross mucus, then centrifuged. The aliquot was then diluted to a concentration of $1 \times 10^{5} \mathrm{cells} / \mathrm{ml}$ and $0.2 \mathrm{ml}$ suspension was spun down onto a glass slide at $1100 \mathrm{rpm}$ for two minutes using a Cytospin cytocentrifuge (Shandon Instruments, Sewickley, Pennsylvania, USA). Slides were then dried and stained using the May-Giemsa method. More than 200 cells were identified using a photomicroscope.

\section{DATA ANALYSIS}

Data were expressed as mean (SE). Differences between groups were compared using the two tailed unpaired Student's $t$ test and MannWhitney U test. Within group differences before and after treatment were compared using the two tailed paired Student's $t$ test or Wilcoxon signed rank test when the Bartlett's test showed non-uniformity of the variance. One way analysis of variance was used for multiple group comparisons. A probability of less than $5 \%$ was considered to be statistically significant.

\section{Results}

CLINICAL FINDINGS

Patients with diffuse panbronchiolitis were divided into two groups as shown in table 1 . Group A consisted of 16 patients (11 men) of mean age 43 (5) years with $P$ aeruginosa in- 
Table 1 Clinical data of individual patients with diffuse panbronchiolitis

\begin{tabular}{|c|c|c|c|c|c|c|c|c|c|c|c|}
\hline Patient no. & $\begin{array}{l}\text { Age } \\
(y)\end{array}$ & $\operatorname{Sex}$ & $\begin{array}{l}\text { Duration of } \\
\text { symptoms }(y)\end{array}$ & $\begin{array}{l}\text { Sputum volume } \\
\text { (ml/day) }\end{array}$ & $V C(\%)$ & $F E V_{1}(l)$ & $\begin{array}{l}F E V_{I} \\
(\%)\end{array}$ & $\begin{array}{l}\mathrm{PaO}_{2} \\
(\mathrm{kPa})\end{array}$ & $\begin{array}{l}\mathrm{PaCO}_{2} \\
(\mathrm{kPa})\end{array}$ & Sinusitis & Smoking habit \\
\hline \multicolumn{12}{|c|}{ Group A $(P$ aeruginosa +$)$} \\
\hline A-1 & 15 & $M$ & 3 & 50 & 53 & $1 \cdot 72$ & 83 & $8 \cdot 4$ & $5 \cdot 8$ & + & Non-smoker \\
\hline$A-2$ & 39 & M & 25 & 400 & 57 & 0.95 & 42 & $8 \cdot 3$ & $6 \cdot 9$ & + & Non-smoker \\
\hline A-3 & 40 & $\mathbf{M}$ & 20 & 50 & 81 & $1 \cdot 88$ & 63 & $8 \cdot 3$ & $5 \cdot 8$ & + & Non-smoker \\
\hline A-4 & 40 & M & 5 & 50 & 82 & 1.97 & 66 & $9 \cdot 6$ & $5 \cdot 8$ & + & Ex-smoker \\
\hline A-5 & 74 & $\mathrm{~F}$ & 10 & 25 & 92 & 1.02 & 51 & $10 \cdot 0$ & $5 \cdot 6$ & + & Non-smoker \\
\hline A-6 & 28 & $\mathbf{M}$ & 14 & 200 & 49 & $0 \cdot 88$ & 47 & $6 \cdot 9$ & $5 \cdot 7$ & + & Non-smoker \\
\hline A-7 & 21 & M & 7 & 25 & 75 & $2 \cdot 45$ & 59 & $10 \cdot 5$ & $5 \cdot 5$ & - & Ex-smoker \\
\hline A-8 & 34 & $M$ & 15 & 10 & 51 & 1.56 & 77 & $12 \cdot 9$ & $4 \cdot 8$ & - & Non-smoker \\
\hline A-9 & 56 & M & 11 & 50 & 67 & 1.23 & 53 & $10 \cdot 1$ & $4 \cdot 8$ & + & Ex-smoker \\
\hline A-10 & 51 & M & 11 & 300 & 76 & 1.97 & 82 & $8 \cdot 4$ & $5 \cdot 5$ & + & Non-smoker \\
\hline A-11 & 60 & $F$ & 3 & 30 & 56 & 0.83 & 63 & $8 \cdot 3$ & $6 \cdot 1$ & + & Non-smoker \\
\hline A-12 & 34 & $\mathbf{M}$ & 8 & 20 & 82 & $2 \cdot 12$ & 65 & $8 \cdot 8$ & $5 \cdot 7$ & + & Non-smoker \\
\hline A-13 & 29 & F & 15 & 100 & 80 & 1.33 & 54 & $10 \cdot 0$ & $5 \cdot 3$ & + & Non-smoker \\
\hline A-14 & 18 & $M$ & 5 & 25 & 62 & $2 \cdot 01$ & 75 & $12 \cdot 4$ & $5 \cdot 3$ & + & Non-smoker \\
\hline A- 15 & 77 & $\mathrm{~F}$ & 3 & 50 & 86 & $1 \cdot 16$ & 69 & $8 \cdot 1$ & $5 \cdot 1$ & + & Non-smoker \\
\hline A-16 & 67 & $\mathrm{~F}$ & 9 & 20 & & 0.81 & 49 & $8 \cdot 8$ & $5 \cdot 3$ & + & Non-smoker \\
\hline Mean (SE) & $43(5)$ & & $10(2)$ & $89(28)$ & $70(4)$ & $1.49(0 \cdot 13)$ & $62(3)$ & $9 \cdot 3(0 \cdot 40)$ & $5 \cdot 6(0 \cdot 13)$ & & \\
\hline \multicolumn{12}{|c|}{ Group B ( $P$ aeruginosa -$)$} \\
\hline B-1 & 41 & $\mathbf{M}$ & 5 & 25 & 61 & 1.56 & 72 & $9 \cdot 5$ & $6 \cdot 1$ & + & Non-smoker \\
\hline B-2 & 60 & $\mathbf{M}$ & 5 & 75 & 97 & 1.98 & 55 & $10 \cdot 4$ & $6 \cdot 1$ & + & Smoker \\
\hline B-3 & 41 & $\mathrm{~F}$ & 5 & 100 & 69 & 1.45 & 78 & $8 \cdot 5$ & $5 \cdot 2$ & + & Non-smoker \\
\hline B-4 & 46 & $M$ & 17 & 20 & 76 & $1 \cdot 20$ & 46 & $9 \cdot 2$ & $5 \cdot 6$ & + & Non-smoker \\
\hline B-5 & 54 & $\mathrm{~F}$ & 2 & 30 & 75 & $2 \cdot 11$ & 91 & 9.9 & $5 \cdot 1$ & + & Non-smoker \\
\hline B-6 & 21 & M & 10 & 10 & 86 & $2 \cdot 89$ & 84 & $12 \cdot 5$ & $5 \cdot 8$ & - & Non-smoker \\
\hline B-7 & 37 & $\mathbf{M}$ & 24 & 70 & 88 & $1 \cdot 88$ & 57 & $8 \cdot 8$ & $5 \cdot 7$ & + & Non-smoker \\
\hline B-8 & 58 & M & 32 & 150 & 77 & 0.98 & 38 & $8 \cdot 7$ & $5 \cdot 2$ & + & Ex-smoker \\
\hline B-9 & 62 & $\mathrm{~F}$ & 2 & 10 & 39 & 0.43 & 47 & $8 \cdot 7$ & $7 \cdot \overline{1}$ & + & Non-smoker \\
\hline B-10 & 63 & $M$ & 8 & 30 & 87 & $1 \cdot 85$ & 66 & $12 \cdot 8$ & $5 \cdot 2$ & + & Ex-smoker \\
\hline B-11 & 49 & $\mathrm{~F}$ & 19 & 60 & 77 & $1 \cdot 23$ & 62 & $10 \cdot 5$ & $6 \cdot 0$ & + & Non-smoker \\
\hline B-12 & 45 & $\mathrm{~F}$ & 6 & 20 & 65 & 0.97 & 57 & $10 \cdot 5$ & $4 \cdot 7$ & + & Non-smoker \\
\hline Mean (SE) & $48(4)$ & & $11(3)$ & $50(12)$ & $75(4)$ & $1.54(0.19)$ & $63(5)$ & $10(0 \cdot 40)$ & $5 \cdot 6(0 \cdot 13)$ & & \\
\hline
\end{tabular}

$\mathrm{VC}=$ vital capacity; $\mathrm{FEV}_{1}=$ forced expiratory volume in one second; $\mathrm{PaO}_{2}, \mathrm{PacO}_{2}=$ arterial oxygen and carbon dioxide tensions.

fection detected before erythromycin therapy (patients A-1 to A-16, table 1). All were nonsmokers or ex-smokers and all except two had chronic sinusitis. Group B consisted of 12 patients (seven men) of mean age 48 (4) years without $P$ aeruginosa infection (patients B-1 to B-12, table 1). All patients except one were non-smokers or ex-smokers and had chronic sinusitis. As summarised in table 1 , there were no differences between groups $\mathrm{A}$ and $\mathrm{B}$ in the duration of symptoms and daily sputum volume. The initial spirometric tests showed no significant differences between both groups with regard to mean $\mathrm{VC}, \mathrm{FEV}_{1}$, and $\mathrm{FEV}_{1} \%$. Hypoxaemia was found in all except two patients in both groups (patients A-8, A-14, B8, B-10, table 1), and the mean $\mathrm{PaO}_{2}$ and $\mathrm{PaCO}_{2}$ were not significantly different between the two groups.

\section{SPUTUM CULTURE}

The organisms identified on sputum culture throughout the 12 month period of erythromycin therapy are shown in table 2 . These organisms were isolated from sputum samples in each patient at least three times during the three month period preceding erythromycin therapy. Sputum cultures were performed 4-10 times during the 12 month treatment period. After the bacterial culture became negative we confirmed that it remained negative on several occasions during the following three months. The culture became negative after erythromycin therapy in five patients in group A (nos A-1 to 5, table 2) and in two patients (nos A6 and A-7, table 2) S pneumoniae or H influenzae were detected on sputum culture although $P$ aeruginosa disappeared.

In group B repeated sputum cultures yielded $H$ influenzae in five patients, $S$ pneumoniae in two, Klebsiella pneumoniae in one, and normal flora in four patients (table 2). Following treatment, sputum cultures became negative for $H$ influenzae and $S$ pneumoniae in four and one patient, respectively, but the latter was replaced with $H$ influenzae. $K$ pneumoniae persisted throughout the treatment period. In all four patients with normal flora the sputum continued to be free from organisms during treatment (nos B-9 to 12 , table 2).

\section{EFFECT OF ERYTHROMYCIN THERAPY ON} RESPIRATORY FUNCTION AND ARTERIAL BLOOD GAS TENSIONS

The effects of erythromycin therapy on respiratory function parameters and arterial blood gas tensions are summarised in table 3. Treatment significantly improved the mean value of all parameters in both groups. There were no significant differences in respiratory function tests and arterial blood gas tensions before or after erythromycin therapy between the two groups. Treatment also made no significant difference in the percentage improvement between the groups. We also compared the changes in respiratory function and arterial blood gas tensions following treatment in patients in whom the bacteria cleared, in those in whom they persisted, and those with a normal flora (table 4). Regardless of the outcome of sputum culture, treatment with erythromycin significantly reduced sputum volume (cleared group: $82.5(36.2)$ to $20.0(9.3) \mathrm{ml}, \mathrm{p}<0.05$, persistent group: $75 \cdot 7(22.9)$ to $3.3(9 \cdot 7) \mathrm{ml}$, $\mathrm{p}<0.05$, normal flora group: $30.0(4.3)$ to 8.75 $(4 \cdot 3) \mathrm{ml}, \mathrm{p}<0.05)$. As shown in table 4, VC, $\mathrm{FEV}_{1}, \mathrm{FEV}_{1} \%$, and $\mathrm{PaO}_{2}$ improved significantly in the group in whom the bacteria cleared. In the other two groups all parameters except $\mathrm{FEV}_{1} \%$ in the group in whom bacteria persisted and VC and $\mathrm{PaO}_{2}$ in the normal flora group improved significantly. Although the rate of 
Table 2 Change of bacteria in sputum of individual patients during treatment with erythromycin

\begin{tabular}{|c|c|c|c|c|c|c|c|c|c|c|c|c|c|}
\hline \multirow{2}{*}{$\begin{array}{l}\text { Patient } \\
\text { no. }\end{array}$} & \multicolumn{13}{|c|}{ Bacteria in sputum (cfu/ml) } \\
\hline & 0 & 1 month & 2 months & 3 months & 4 months & 5 months & 6 months & 7 months & 8 months & 9 months & 10 months & 11 months & 12 months \\
\hline \multicolumn{14}{|c|}{ Group A $(P$ aeruginosa +$)$} \\
\hline A-1 & $P A^{\circ}$ & & PA & PA & & & PA & & & & & & $\mathrm{NF}^{*}$ \\
\hline A-2 & PA & PA & & PA & & $\mathrm{NF}^{*}$ & NF & & & & NF & NF & NF \\
\hline A-3 & PA & & PA & PA & & PA & & & & PA & & PA & $\mathrm{NF}^{*}$ \\
\hline A-4 & PA & & PA & & & & PA & & $\mathrm{NF}^{*}$ & & & & $\mathrm{NF}$ \\
\hline A-5 & PA & $\mathrm{NF}^{*}$ & & NF & $\mathrm{D}$ & $\mathrm{D}$ & $\mathrm{D}$ & D & $\mathrm{D}$ & $\mathrm{D}$ & $\mathrm{D}$ & $\mathrm{D}$ & $\mathrm{D}$ \\
\hline A-6 & PA & & PA & & PA & & & PA & & SP & & SP & SP \\
\hline A-7 & PA & PA & & PA & & & PA & & & & PA & & HI \\
\hline A-8 & PA & & & PA & & & PA & & & PA & & & PA \\
\hline A-9 & PA & PA & & & PA & & & & & PA & & & PA \\
\hline A-10 & PA & PA & PA & PA & PA & & PA & PA & PA & PA & PA & PA & PA \\
\hline A-11 & PA & & & PA & & PA & PA & & & & PA & & PA \\
\hline A-12 & PA & & & PA & & & PA & & & PA & & & PA \\
\hline A-13 & PA & PA & & PA & & & PA & & PA & & & & PA \\
\hline A-14 & PA & & & PA & & PA & & & & & PA & & PA \\
\hline A-15 & PA & & PA & & PA & & & PA & & PA & & & PA \\
\hline A-16 & PA & & PA & & & PA & & & PA & & & & PA \\
\hline \multicolumn{14}{|c|}{ Group B ( $P$ aeruginosa -$)$} \\
\hline B-1 & $\mathrm{HI}$ & & HI & & HI & $\mathrm{NF}^{*}$ & & $\mathrm{NF}$ & & & & HI & $\mathrm{NF}$ \\
\hline B-2 & $\mathrm{HI}$ & $\mathrm{HI}$ & HI & & HI & & $\mathrm{HI}$ & & & HI & & $\mathrm{HI}$ & $\mathrm{NF}^{*}$ \\
\hline B-3 & HI & HI & & HI & & $\mathrm{NF}^{*}$ & NF & & & & NF & & $\mathrm{NF}$ \\
\hline B-4 & HI & $\mathrm{NF}^{*}$ & & & & & D & D & D & D & D & D & D \\
\hline B-5 & SP & & SP & $\mathrm{NF}^{*}$ & & & NF & & & NF & & & $\mathrm{NF}$ \\
\hline B-6 & SP & SP & & HI & HI & & HI & & & HI & & & HI \\
\hline B-7 & HI & & & HI & & & HI & & & & HI & & HI \\
\hline B-8 & $\mathrm{KP}$ & & $\mathrm{KP}$ & & $\mathrm{KP}$ & & & & KP & & & & KP \\
\hline B-9 & $\mathrm{NF}$ & & & NF & & & NF & & & NF & & & NF \\
\hline B-10 & $\mathrm{NF}$ & NF & & $\mathrm{NF}$ & & & NF & & & & NF & & NF \\
\hline B-11 & NF & & & NF & & & & & & NF & & & NF \\
\hline B-12 & $\mathrm{NF}$ & & NF & & NF & & & NF & & & NF & & NF \\
\hline
\end{tabular}

$\mathrm{PA}=P$ aeruginos $; \mathrm{HI}=H$ influenzae $; \mathrm{SP}=S$ pneumoniae $\mathrm{KP}=K$ pneumoniae $\mathrm{NF}=$ normal flora $\mathrm{D}=$ bacteria disappeared.

* First occasion on which the bacterial culture became negative after erythromycin therapy.

Table 3 Mean (SE) respiratory function tests and blood gas tensions before and after erythromycin therapy in patients infected with $P$ aeruginosa (group $A$ ) and those not infected (group B)

\begin{tabular}{|c|c|c|c|c|c|}
\hline & $V C(\%)$ & $F E V_{I}$ (l) & $F E V_{l}(\%)$ & $\mathrm{PaO}_{2}(\mathrm{kPa})$ & $\mathrm{PaCO}_{2}(k P a)$ \\
\hline \multicolumn{6}{|l|}{$\begin{array}{l}\text { Group A }(P \text { aeruginosa }+) \\
(n=16)\end{array}$} \\
\hline Before & $70 \cdot 4(3 \cdot 5)$ & $1.49(0 \cdot 13)$ & $62 \cdot 4(3 \cdot 2)$ & $9 \cdot 3(0 \cdot 40)$ & $5 \cdot 6(0 \cdot 13)$ \\
\hline After & $88.5(3.6)^{*}$ & $2.07(0.18)^{*}$ & $69.4(3.9)^{* * * *}$ & $10.9(0.35)^{*}$ & $5 \cdot 5(0 \cdot 12)$ \\
\hline Percentage improvement (\%) & $28 \cdot 7(6 \cdot 5)$ & $41 \cdot 7 \quad(7 \cdot 3)$ & $12 \cdot 1(4 \cdot 1)$ & $18 \cdot 0(3 \cdot 9)$ & \\
\hline \multicolumn{6}{|l|}{$\begin{array}{l}\text { Group B }(P \text { aeruginosa }-) \\
(\mathrm{n}=12)\end{array}$} \\
\hline Before & $74 \cdot 7(4 \cdot 4)$ & $1 \cdot 54(0 \cdot 19)$ & $62 \cdot 7(4 \cdot 6)$ & $10 \cdot 0(0 \cdot 43)$ & $5 \cdot 7(0 \cdot 19)$ \\
\hline After & $92 \cdot 4(4 \cdot 9)^{* * * *}$ & $2 \cdot 10(0 \cdot 19)^{* * *}$ & $70 \cdot 3(4 \cdot 1)^{* * * *}$ & $11.2(0.37)^{* * * *}$ & $5 \cdot 6(0 \cdot 11)$ \\
\hline Percentage improvement (\%) & $29 \cdot 6(12 \cdot 0)$ & $50 \cdot 1 \quad(16.9)$ & $14 \cdot 1(4 \cdot 6)$ & $13 \cdot 3(5 \cdot 1)$ & \\
\hline
\end{tabular}

Table 4 Mean (SE) respiratory function tests and blood gas tensions before and after erythromycin therapy in patients in whom $P$ aeruginosa infection cleared, those in whom it persisted, and those with normal flora

\begin{tabular}{|c|c|c|c|c|c|}
\hline & $V C(\%)$ & $F E V_{l}$ (l) & $F E V_{1}(\%)$ & $\mathrm{PaO}_{2}(\mathrm{kPa})$ & $\mathrm{PaCO}_{2}(\mathrm{kPa})$ \\
\hline \multicolumn{6}{|l|}{ Cleared group $(n=10)$} \\
\hline Before & $74 \cdot 3(4 \cdot 6)$ & $1 \cdot 58(0 \cdot 13)$ & $64 \cdot 6(5 \cdot 2)$ & $9 \cdot 2(0 \cdot 25)$ & $5 \cdot 8(0 \cdot 16)$ \\
\hline After & $92 \cdot 3(4 \cdot 0)^{*}$ & $2 \cdot 31(0 \cdot 21)^{*}$ & $73 \cdot 5(5 \cdot 5) * * * *$ & $10.9(0.43)^{* * *}$ & $5.8(0.09)$ \\
\hline Percentage improvement (\%) & $26 \cdot 8(6 \cdot 0)$ & $47 \cdot 4(8 \cdot 2)$ & $15 \cdot 2(5 \cdot 4)$ & $19 \cdot 5(6 \cdot 1)$ & \\
\hline \multicolumn{6}{|l|}{ Persistent group $(n=14)$} \\
\hline Before & $72 \cdot 3(3 \cdot 5)$ & $1 \cdot 58(0 \cdot 18)$ & $62 \cdot 3(3 \cdot 7)$ & $9 \cdot 7(0.49)$ & $5 \cdot 4(0 \cdot 11)$ \\
\hline After & $86 \cdot 6(4 \cdot 8)^{* * * *}$ & $1.97(0.20)^{* *}$ & $66 \cdot 0(3 \cdot 6)$ & $11.0(0.35)^{* *}$ & $5.4(0.09)$ \\
\hline Percentage improvement (\%) & $22 \cdot 4(8 \cdot 1)$ & $28 \cdot 7(6 \cdot 9)$ & $7 \cdot 2(3 \cdot 4)$ & $15 \cdot 4(3 \cdot 8)$ & \\
\hline \multicolumn{6}{|l|}{ Normal flora group $(n=4)$} \\
\hline Before & $67 \cdot 0(10 \cdot 2)$ & $1 \cdot 12(0 \cdot 30)$ & $58 \cdot 0(4 \cdot 0)$ & $10 \cdot 6(0 \cdot 85)$ & $5 \cdot 8(0.09)$ \\
\hline After & $97 \cdot 7(5 \cdot 4)$ & $1.89(0.23)^{* *}$ & $73 \cdot 5(4 \cdot 6)^{* * * *}$ & $11.5(0.83)$ & $5 \cdot 3(0 \cdot 20)$ \\
\hline Percentage improvement (\%) & $58 \cdot 1(28 \cdot 3)$ & $98 \cdot 0(42 \cdot 0) \dagger$ & $27 \cdot 7(7 \cdot 1) \dagger$ & $9 \cdot 3(9 \cdot 5)$ & \\
\hline
\end{tabular}

$\mathrm{VC}=$ vital capacity; $\mathrm{FEV}_{1}=$ forced expiratory volume in one second; $\mathrm{PaO}_{2}, \mathrm{PaCO}_{2}=$ arterial oxygen and carbon dioxide tensions. $* \mathrm{p}<0.001, * * \mathrm{p}<0.005, * * * \mathrm{p}<0.01,{ }^{* * * *} \mathrm{p}<0.05$ compared with the finding before erythromycin therapy.

$+p<0.05$ compared with the rate of improvement [(value after therapy - value before therapy)/value before therapy $\times 100)$ ] in the persistent group.

improvement in $\mathrm{FEV}_{1}$ and $\mathrm{FEV}_{1} \%$ between the group in whom the bacteria persisted and those with normal flora showed significant differences, there were no significant differences in all parameters before or after treatment among the three groups.
EFFECT OF ERYTHROMYCIN THERAPY ON BAL FLUID

BAL was performed in five patients in group A $(\mathrm{A}-1,2,3,8,12)$ and in nine in group $\mathrm{B}(\mathrm{B}-$ 1-4, 6, 8, 10-12) before and after 12 months of erythromycin therapy. The mean per- 

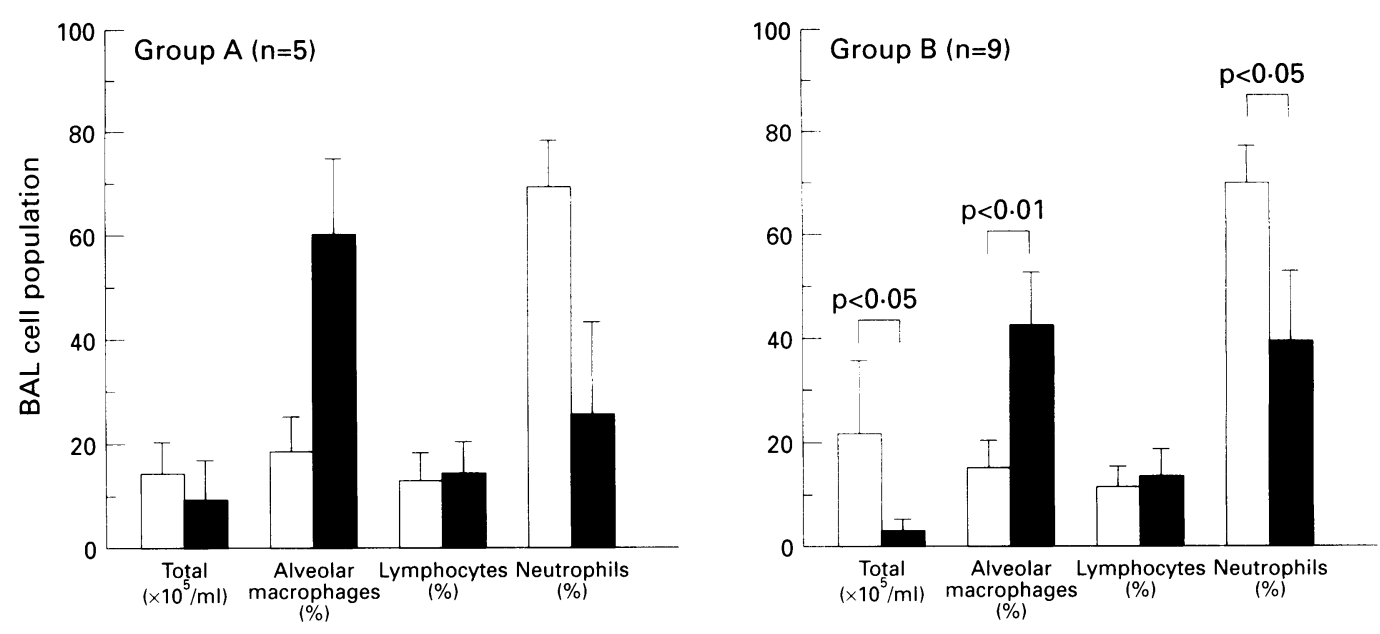

Figure 1 Differential cell count in BAL fluid of patients in group $A$ (with $P$ aeruginosa infection) and group $B$ (without $P$ aeruginosa infection) before $(\square)$ and after ( $\square$ ) treatment with erythromycin.

centages of cells in the BAL fluid are shown in fig 1 . Although there was a trend for a reduction in the total cell count $\left(13 \cdot 7(4 \cdot 2) \times 10^{5}\right.$ to $8 \cdot 3$ $(6 \cdot 4) \times 10^{5}$ cells $\left./ \mathrm{ml}\right)$ and the percentage of neutrophils $(69 \cdot 3(7 \cdot 7) \%$ to $25 \cdot 6(16 \cdot 4) \%)$ and an increase in the percentage of alveolar macrophages $(18 \cdot 1(5 \cdot 2) \%$ to $59 \cdot 8(13 \cdot 7) \%)$ in patients in group $\mathrm{A}$, the differences were not statistically significant. In patients in group B treatment with erythromycin significantly reduced the total cell number $\left(22 \cdot 1(13 \cdot 0) \times 10^{5}\right.$ to $\left.3 \cdot 5(0 \cdot 9) \times 10^{5} \mathrm{cells} / \mathrm{ml}\right)$ and the percentage of neutrophils $(71.2(5 \cdot 5) \%$ to $40.6(11.7) \%$, $\mathrm{p}<0.05)$ and increased the percentage of alveolar macrophages $(15 \cdot 8(3.7) \%$ to 43.5 $(8.4) \%, \mathrm{p}<0.05)$. There were no significant differences in the total cell number or the percentage of neutrophils and alveolar macrophages in BAL fluid between the two groups before and after treatment with erythromycin.

Figure 2 shows the effect of erythromycin therapy on BAL fluid parameters. In the group in whom the bacteria cleared $(n=7)$, treatment with erythromycin significantly reduced the mean total cell number from a control value of $24.3(16 \cdot 8) \times 10^{5}$ to $2 \cdot 2(0 \cdot 6) \times 10^{5} \mathrm{cells} / \mathrm{ml}$ $(p<0.01)$ and the percentage of neutrophils from $71.2(5.5) \%$ to $40.6(11.7) \%(\mathrm{p}<0.01)$, associated with a significant increase in alveolar macrophages $(16.5(11.4) \%$ to $48 \cdot 4(10.9) \%$, $\mathrm{p}<0.05)$. In the other two groups the changes were not significant.

\section{Discussion}

In 1984 Kudoh et al first reported that low dose and long term treatment with erythromycin was effective in chronic lower respiratory tract infections including diffuse panbronchiolitis. ${ }^{18}$ Recently, several investigators ${ }^{23-25}$ have also shown similar clinical benefits using roxithromycin and clarithromycin, two new erythromycin derivatives. Before that time patients with diffuse panbronchiolitis were treated with corticosteroids in the early stage followed by administration of appropriate antibiotics. However, most patients suffered from persistent infection and the condition progressed insidiously. The prognosis was considered poor, especially after infection with $P$ aeruginosa, and the 10 year survival rate in cases infected with $P$ aeruginosa was about one sixth of that of the
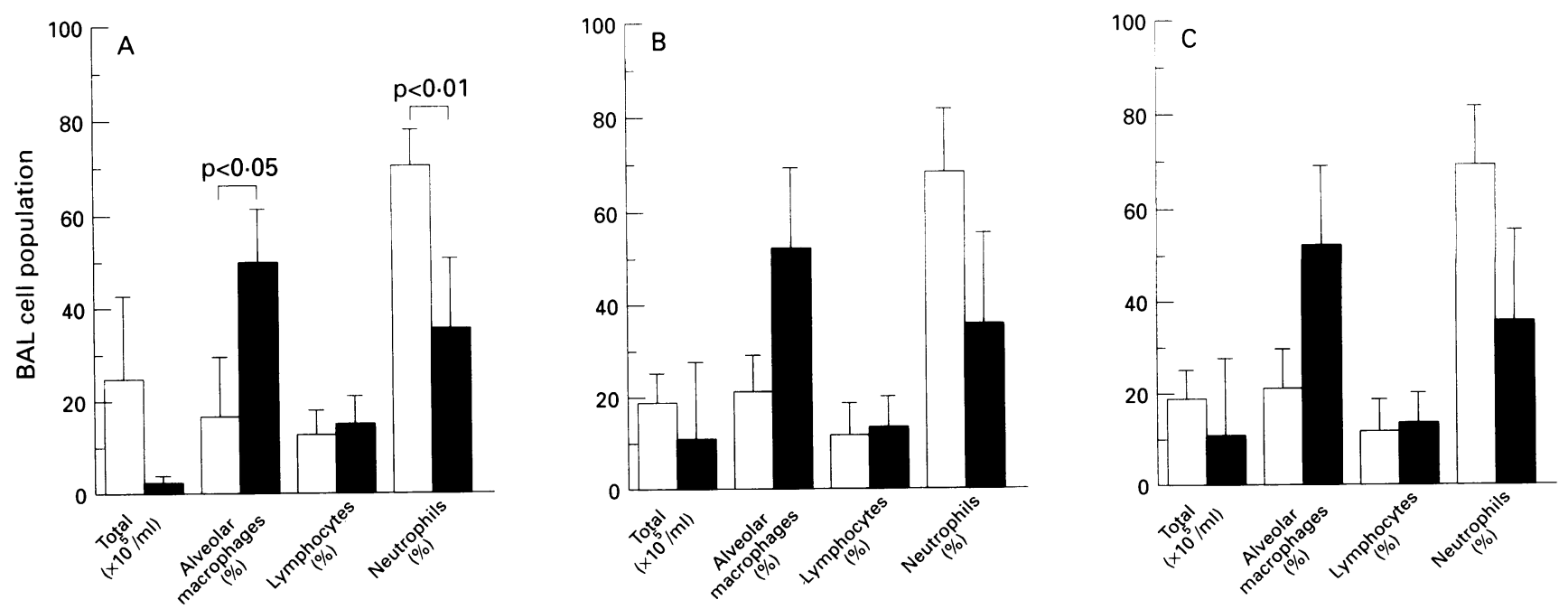

Figure 2 Differential cell count in BAL fluid in $(A)$ patients with diffuse panbronchiolitis in whom P aeruginosa cleared $(n=7)$, (B) those in whom $P$ aeruginosa infection persisted, and $(C)$ the group with normal flora before $(\square)$ and after $(\square)$ treatment with erythromycin. 
cases without $P$ aeruginosa infection. Treatment with erythromycin improved the prognosis of patients with diffuse panbronchiolitis and increased the 10 year survival rate to more than $90 \% .{ }^{20}$ Erythromycin caused a significant improvement in clinical symptoms, the chest radiograph, respiratory function tests, and arterial blood gas tensions compared with those treated with a new quinolone antibacterial agent for more than three months ${ }^{26}$ or with ampicillin for three months. ${ }^{27}$ The Research Project Team of the Ministry of Health and Welfare for Specific Disease in Japan recently conducted a double blind comparative study with placebo on the use of erythromycin in diffuse panbronchiolitis. Treatment for three months produced a significant clinical improvement. ${ }^{28}$ In these reports the effect of erythromycin therapy was investigated only at three month intervals. We examined retrospectively the clinical benefits of this treatment for 12 months and the result extensively confirmed the previous reports. Furthermore, no previous study has compared the effect of erythromycin in patients with and without $P$ aeruginosa infection. In our study it was of interest that, irrespective of $P$ aeruginosa infection, the change in respiratory function tests and arterial blood gas tensions before and after erythromycin therapy made no significant differences to the rate of improvement in all parameters. This result shows that erythromycin may be effective in diffuse panbronchiolitis even if the patient is already colonised with $P$ aeruginosa, and the prognosis is good regardless of $P$ aeruginosa infection. However, since this study was performed retrospectively and was restricted to 12 months, the actual course of the chronic disease is difficult to predict. We therefore believe that a long term prospective study should be performed in the future.

In this study treatment with erythromycin was clinically effective whether or not there was bacterial clearance, as $P$ aeruginosa was cleared in seven of the 16 patients $(43.8 \%)$ although the maximum therapeutic serum and sputum concentrations of the drug at an oral dose of $600 \mathrm{mg} /$ day are below the minimum inhibitory concentration for $P$ aeruginosa. ${ }^{29}$ It has also been reported that $P$ aeruginosa is often cleared with a clearance rate of $25.9 \%$ (seven of 25 ), ${ }^{23}$ and $80 \%$ (four of five). ${ }^{29}$ This could not be confirmed by our study, although many investigators have reported that the effect of erythromycin is mediated through its action on the causative bacteria - for example, inhibition of elastase production by $P$ aeruginos $a,{ }^{1730}$ reduction of bacterial adherence correlating with reduced production of pilli of $P$ aeruginos $a^{31}$ and the destruction of $P$ aeruginosa biofilm. ${ }^{27} 32$ The destructive effect of macrolides on the biofilm has recently attracted particular attention. Interestingly, erythromycin therapy reduced sputum volume independent of bacterial clearance. Such an effect may be mediated by the inhibitory effect of erythromycin on respiratory glycoconjugate secretion ${ }^{33}$ or airway hypersecretion. ${ }^{34}$

Treatment with erythromycin reduced the total cell number and the percentage of neu- trophils in BAL fluid independent of bacterial clearance. The excessive accumulation of neutrophils in the airway is injurious to lung parenchyma, epithelial cells, and tracheal explants because of the oxidative and proteolytic enzymes. ${ }^{35-37}$ Using gel filtration chromatography Oda et $a l^{\beta 8}$ have recently reported that the neutrophil chemotactic activity shows four peaks in the elution profile; it was increased in BAL fluid obtained from patients with diffuse panbronchiolitis but was significantly reduced after treatment with erythromycin. Furthermore, Oishi et $a l^{\beta 9}$ have also shown a moderate inhibitory effect of erythromycin on IL-8 production in Pseudomonas stimulated neutrophils but not in alveolar macrophages. Thus, anti-inflammatory mechanisms other than those involving destruction of the bacterial biofilm may explain the beneficial effect of erythromycin and other macrolides in diffuse panbronchiolitis. When combined, the results of these studies suggest that erythromycin may act first by reducing neutrophil migration and then by inhibiting inappropriate and excessive inflammation in the lower respiratory tract.

In conclusion, our results indicate that treatment with erythromycin produces clinical improvement in patients with diffuse panbronchiolitis independent of $P$ aeruginosa infection. Although the mode of action was not investigated in the present study, our results suggest that erythromycin may act through its anti-inflammatory properties rather than through its antibacterial effect. Further prospective studies are required to confirm these findings.

We thank the staff at Word-Medex (Sydney, Australia) for their assistance in editing the manuscript.

1 Yamanaka A, Saeki S, Saito K. The problems in chronic obstructive pulmonary disease: especially concerning about diffuse panbronchiolitis. Intern Med 1969;23:44251.

2 Rnadhawa P, Hoagland $\mathrm{MH}$, Yousem SA. Diffuse panbronchiolitis in North America: report of three cases and bronchiolitis in North America: report of three cases and
review of the literature. Am $\mathcal{F}$ Surg Pathol 1991;15:43-7.

3 Poletti V, Patelli M, Poletti G, Bertanti T, Spiga L. Diffuse panbronchiolitis observed in an Italian. Chest 1990;98 515-6.

4 Suzaki S, Kudoh S, Sugiyama Y, Maeda H. HLA antigens in sinobronchial syndrome. $\mathcal{f} \mathfrak{f p n}$ Bronchoesophagol Soc 1983;34:270-7.

5 Homma H, Yamanaka A, Tanimoto S, Tamura M, Chijimatsu Y, Kira S, et al. Diffuse panbronchiolitis: a disease of the transitional zone of the lung. Chest 1983;83:63-9.

6 Nakata K, Inatomi T. Annual report on the study of diffuse disseminated lung disease. Ministry of Health and Welfare in Japan, 1981.

7 Kadota J, Sakito O, Kohno S, Sawa H, Mukae H, Oda H, et al. A mechanism of erythromycin treatment in patients with diffuse panbronchiolitis. Am Rev Respir Dis 1993; 147:153-9.

8 Buret A, Cripps AW. The immunoevasive activities of $P$ aeruginosa: relevance for cystic fibrosis. Am Rev Respir Dis 1993;148:793-805.

9 McGowan KL. The microbiology associated with cystic fibrosis. Clin Microbiol Rev 1988;10:9-13.

10 Nagaki M, Shimura S, Tanno Y, Ishibashi T, Sakaki H, Takishima T. Role of chronic $P$ aeruginosa infection in the development of bronchiectasis. Chest 1992;102:1464-9.

11 Liu PV. The roles of various fractions of $P$ aeruginosa in its pathogenesis. III. Identity of the lethal toxin produced in
pathe roles of vitro and in vivo. $\mathcal{F}$ Infect Dis 1966;116:481-9.

12 Morihara $\mathrm{K}$, Tsuzuki H, Oka T, Inoue $\mathrm{H}$, Ebata $M$. $P$ aeruginosa elastase: isolation, crystallization and preliminary characterization. $\mathcal{F}$ Biol Chem 1965;240:3295304

13 Stutts MJ, Schwab JH, Chen MG, Knowles MR, Boucher RC. Effects of $P$ aeruginosa on bronchial epithelial ion transport. Am Rev Respir Dis 1986;134:17-21.

14 Lapa e Silva JR, Guerreiro D, Noble B, Poulter LW, Cole PJ. Immunopathology of experimental bronchiectasis. $\mathrm{Am}$ f Respir Cell Mol Biol 1989;1:297-304.

15 McCord JM, Fridovich I. The biology and pathology of oxygen radicals. Ann Intern Med 1987;89:122-7. 
16 Lee CT, Fein AM, Lippmann M, Holtzman H, Kimbel P, Weinbaum $\mathrm{G}$. Elastolytic activity in pulmonary lavage fluid from patients with adult respiratory distress syndrome. $N$ Engl $\mathcal{f}$ Med 1981;304:192-6.

17 Sakata K, Yajima H, Tanaka K, Sakamoto T, Yamamoto $\mathrm{K}$, Yoshida A, et al. Erythromycin inhibits the production of elastase by Pseudomonas aeruginosa without affecting its proliferation in vitro. Am Rev Respir Dis 1993;148:1061-5.

proliferation in vitro. Am Rev Respir Dis 1993;148:1061-5.
18 Kudoh S, Uetake T, Hagiwara K, Hirayama M, Hus L Kimura $\mathrm{H}$, et al. Clinical effect of low-dose long-term erythromycin chemotherapy on diffuse panbronchiolitis. fpn Thorac Dis 1987;25:632-42.

19 Sawaki M, Mikami R, Mikasa K, Kunimatu M, Ito S, Narita $\mathrm{N}$. The long term chemotherapy with erythromvcin in chronic lower respiratory tract infections. Second report: including cases with Pseudomonas aeruginosa infections. $\mathcal{F}$ fpn Assoc Infect Dis 1986;60:45-50.

20 Høiby N. Diffuse panbronchiolitis and cystic fibrosis: East meets West. Thorax 1994;49:531-2

21 Pirtle JK, Monroe PW, Smalley TK. Diagnosis and therapeutic advantages of serial quantitative cultures of fresh sputum in acute bacterial pneumonia. Am Rev Respir Dis 1969;100:831-8.

22 Monroe PW, Muchmore HG, Felton GF, Pirtle JK. Quantitation of microorganisms in sputum. Appl Microbiol 1969, 18:214-20.

23 Kadota J, Sakito O, Kohno S, Abe K, Shirai R, Kawakami $\mathrm{K}$, et al. Roxithromycin treatment in patients with chronic lower respiratory tract disease - its clinical efficacy and

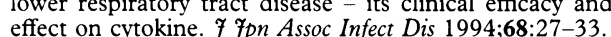

24 Takeda H, Oogaki N, Kikuchi N, Kobayashi H, Akashi T. A study to clarify the mechanism of the usefulness of the macrolides: the influence of clarithromycin to biofilm with $P$ aeruginosa. F Jpn Assoc Infect Dis 1992;66:1454-61.

25 Mikasa K, Sawaki M, Kita E, Konishi M, Maeda K, Hamada $\mathrm{K}$, et al. Long-term chemotherapy using erythromycin for chronic lower airway infection: effectiveness of clarithromycin in erythromycin ineffective cases - the fourth report. 7 Jpn Assoc Infect Dis 1992;66:1097-104.

26 Yamamoto M, Kondo A, Tamura M, Izumi T, Ina Y, Noda $M$. Long-term therapeutic effects of erythromycin and new quinolone antibacterial agents on diffuse panbronchiolitis. quinolone antibacterial agents on diffus

27 Ichikawa Y, Ninomiya H, Koga H, Tanaka M, Kinoshita M, Tokunaga N, et al. Erythromycin reduces neutrophils and neutrophil-derived elastolytic-like activity in the lower respiratory tract of bronchiolitis patients. Am Rev Respir Dis 1992;146:196-203.

28 Yamamoto M. Annual report on the study of diffuse disseminated lung disease. Ministry of Health and Welfare in Japan, 1991.

29 Nagai H, Shishido H, Yoneda R, Yamaguchi E, Tamura A, Kurashima A, et al. Long-term low-dose administration of erythromycin to patients with diffuse panbronchiolitis. Respiration 1991;58:145-9.

30 Masutani T, Sawaki M, Mikasa K, Konishi M, Yagyu Y, Narita N, et al. Inhibitory effect of erythromycin on elastase producing ability of Pseudomonas aeruginosa. $7 \mathrm{Fpn}$ Assoc Infect Dis 1989;63:1212-4.

31 Yamasaki T. Adherence of Pseudomonas aeruginosa to mouse tracheal epithelium. The effect of antimicrobial agents. $\mathcal{F}$ fpn Assoc Infect Dis 1990;64:575-83.

32 Yasuda $\mathrm{H}$, Ajiki Y, Koga T, Kawada $\mathrm{H}$, Yokota $\mathrm{T}$. Interaction between biofilm formed by Pseudomonas aeruginosa and clarithromycin. Antimicrob Chemother 1993;37:1749-55.

33 Goswami SK, Kivity S, Marom Z. Erythromycin inhibits respiratory glycoconjugate secretion from human airways in vitro. Am Rev Respir Dis 1990;141:72-8.

34 Tamaoki J, Isono K, Sakai N, Kanemura T, Konno K. Erythromycin inhibits $\mathrm{Cl}$ secretion across canine tracheal epithelial cells. Eur Respir F 1992;5:234-8.

35 Weiland JE, Davis WB, Holter JF, Mohammed JR, Dorinsky PM, Gadek JE. Lung neutrophils in the adult respiratory distress syndrome: clinical and pathophysiologic significance. Am Rev Respir Dis 1986;133:218-25.

36 Cantin AM, North SL, Fells GA, Hubbart RC, Crystal RG. Oxidant-mediated epithelial cell injury in idiopathic pulmonary fibrosis. I Clin Invest 1987;79:1665-73.

37 Mohammad JR, Mohammad BS, Pawluk LJ, Bucci DM Baker NR, Davis WB. Purification and cytotoxic potential of myeloperoxidase in cystic fibrosis sputum. $7 \mathrm{Lab} \mathrm{Clin}$ Med 1988;112:711-20.

38 Oda H, Kadota J, Kohno S, Hara K. Erythromycin inhibits neutrophil chemotaxis in bronchoalveoli of diffuse panbronchiolitis. Chest 1994;106:1116-23.

39 Oishi K, Sonoda F, Kobayashi S, Iwagaki A, Nagatake T, Matsushima K, et al. Role of interleukin-8 (IL-8) and an inhibitory effect of erythromycin on IL-8 release in the inhibitory effect of erythromycin on $\mathrm{IL}-8$ release in the
airways of patients with chronic airway diseases. Infect Inmun 1994;62:4145-52. 